\title{
Relevance of clinical features in the prognosis of bronchopulmonary dysplasia in premature infants
}

\author{
ZHIFANG DU ${ }^{1-3^{*}}$, XIANGYONG KONG ${ }^{1,2^{*}}$, YANLI REN $^{1,2,4}$, \\ ZHICHUN FENG ${ }^{1,2}$, JUNJIN HUANG ${ }^{1,2}$, JIA CHEN $^{1,2}$ and RUIJUAN WANG ${ }^{1,2}$
}

\author{
${ }^{1}$ Newborn Care Center, Affiliated Bayi Children's Hospital, Clinical Medical College in PLA-Army General Hospital, Southern \\ Medical University; ${ }^{2}$ Beijing Key Laboratory of Pediatric Organ Failure, Beijing 100007; \\ ${ }^{3}$ Department of Pediatrics, PLA Bethune International Peace Hospital, Shijiazhuang, \\ Hebei 050082; ${ }^{4}$ Department of Neonatology, Teaching Hospital of Fujian Medical University, \\ Fujian Maternity and Children Health Hospital, Fuzhou, Fujian 350001, P.R. China
}

Received April 19, 2016; Accepted April 7, 2017

DOI: $10.3892 /$ etm.2017.4985

\begin{abstract}
The aim of this study is to determine the accuracy rate of bronchopulmonary dysplasia (BPD) diagnosis and risk factors of short-term poor prognosis for premature infants. This study analyzed the clinical data of 81 premature infants ( $<32$ weeks gestational age) with BPD, who were on oxygen therapy $>28$ days, and survived $>36$ weeks (corrected age). Outcome measures included treatments, conditions on the 28th day after birth, oxygen therapy conditions at the 36th week, occurrence of any serious complications during hospital stay. The major risk factors affecting prognosis were ventilation duration, duration of oxygen therapy, application of steroids, hypothyroidism and severity of BPD (all P<0.05). Interventions for complications $(\mathrm{n}=53)$ resulted in ceased inhalation of oxygen in 12 infants, improvement of symptoms in 26 infants, and were ineffective in 15 infants. BPD prognosis can be improved by shortening the duration of invasive ventilation and correcting thyroid function.
\end{abstract}

\section{Introduction}

Bronchopulmonary dysplasia (BPD) is a chronic respiratory disease that develops in extremely low birth weight (ELBW) and very low birth weight (VLBW) infants born with severe respiratory distress syndrome (RDS) (1). It is caused by perinatal/neonatal lung injury and repair resulting

Correspondence to: Dr Zhichun Feng, Newborn Care Center, Affiliated Bayi Children's Hospital, Clinical Medical College in PLA-Army General Hospital, Southern Medical University, 5 South Gate, Dongsi Shitiao, Do Cheng, Beijing 100007, P.R. China

E-mail: zhjfengzc@126.com

*Contributed equally

Key words: bronchopulmonary dysplasia, premature, diagnosis, prognosis, ventilation from mechanical ventilation and oxygen therapy $(1,2)$, and is characterized by airway injury and parenchymal fibrosis (2). The type and timing of respiratory support are considered to play a role in development of BPD (3). Factors such as genetic variations in surfactant proteins, fetal and neonatal infections, and polymorphisms of genes encoding vascular endothelial growth factors are also thought to contribute to the development of BPD (4). Inconsistent standards for BPD diagnosis have resulted in the definition of BPD changing over the past 40 years. The classic diagnostic criteria for BPD include i) premature birth, ii) presence of RDS, iii) history of mechanical ventilation using a high concentration of oxygen and high airway pressure, iv) consistent oxygen assistance for $>28$ days, and v) alterations in chest X-rays (5). Histological studies of lung tissue from these infants have exhibited parenchymal fibrosis, inflammation and smooth muscle hypertrophy leading to diffuse airway damage (6).

The introduction of prenatal glucocorticoid therapy, postnatal surfactant therapy, gentler ventilation strategies and the use of continuous positive airway pressure with selective surfactant have resulted in a decreased incidence of classic BPD over the past two decades, particularly in infants born at $>30$ weeks of gestation (7-9). Despite these advances, some VLBW infants who initially had minimal lung disease developed progressively worsening pulmonary function following mechanical ventilation for a few days or weeks. Histological examination of the tissues from these infants identified less fibrosis, fewer and larger alveoli, and significantly less epithelial metaplasia and smooth muscle hypertrophy in the small and large airways compared with that for the old diagnostic standards of BPD $(1,10)$. The new definition of BPD is based on the requirement for supplemental oxygen at 36 weeks of corrected gestational age, positive pressure requirements and the gestational age of the infant (11-13), and has a severity grade based on the level of respiratory support that is required, as follows: Mild, supplemental oxygen requirement at $>28$ days but not at 36 weeks postmenstrual age (PMA); moderate, supplemental oxygen requirement at $>28$ days and $<30 \%$ at 36 weeks PMA; severe, supplemental oxygen requirement at $>28$ days and $>30 \%$ at 36 weeks PMA and/or positive pressure 
at 36 PMA (1). However, BPD defined solely by the duration of oxygen therapy has been shown to be an inaccurate indicator of long-term pulmonary and neurological outcomes $(14,15)$.

Currently, BPD is most frequently diagnosed in premature infants of gestational age $<30$ weeks and weight $<1,000 \mathrm{~g}$, and a BPD diagnosis identifies infants who are most at risk of respiratory problems in childhood, and sometimes adulthood $(7,16,17)$. Since BPD is frequently associated with growth retardation, recurrent infection of the lower respiratory tract, neuro-developmental delays, cognitive impairment and retinopathy of prematurity (ROP), it places a significant burden on the health care system, and is one of the major challenges faced in neonatal intensive care units $(7,16,17)$. Ascertaining the accuracy rate of a BPD diagnosis, evaluating the relationship between its clinical features and the long-term prognosis, and development of a prognostic model are therefore critical goals to assist the clinician in estimating the probable disease course, and identifying patients who are likely to benefit from interventions.

The present study retrospectively analyzed the clinical data of 81 premature infants diagnosed with BPD ( $<32$ weeks gestational age), and investigated the significant risk factors of short-term poor prognosis.

\section{Patients and methods}

Patients. This study has been approved by the institutional review board of Beijing Military General Hospital (Beijing, China). Informed consent was obtained from all individual participants included in the study.

This retrospective study evaluated data from 746 premature infants (gestational age $<32$ weeks) who received oxygen therapy between June 2012 and December 2013 at the neonatal intensive care unit of the Bayi Children's Hospital affiliated to Army General Hospital. Premature infants who received oxygen therapy for $>28$ days, survived for $>36$ weeks (PMA) and who have 12-month follow-up assessments were included in the study. Premature infants whose age on admission was $>14$ days were excluded. Based on the inclusion and exclusion criteria, a total of 81 premature infants were enrolled in this study.

Clinical data. The clinical data of the 81 premature infants diagnosed with BPD were recorded. Data recorded included general perinatal information (gender, gestational age, whether the infant was a singleton or from a multiple birth, presence of intra-uterine infections and time of premature membrane rupture); treatment (invasive ventilation duration, non-invasive ventilation duration, duration of oxygen therapy, first time of application of steroids and steroids course prescribed); conditions on day 28 after birth (oxygen therapy, existence of complications causing oxygen reliance and effects of complications management); oxygen therapy conditions at week 36 after birth; degree of BPD based on the criteria of the National Institute of Child Health and Human Development (NICHD) (12); tests conducted (chest X-ray, cardiac ultrasound, computed tomography of the thorax, full blood counts and arterial blood gas analysis); occurrence of any serious complications during hospital stay, including ROP, greater than third degree intracranial hemorrhage, pulmonary hemorrhage or hypothyroidism. The major goals of complication management over the 28-day time period included cessation of oxygen therapy, and improvement of conditions as measured by transition from invasive to non-invasive therapy, non-invasive therapy to the use of an oxygen mask, and decrease in the concentration of oxygen therapy.

All 81 study subjects were followed up until a corrected age of 12 months. Follow-up visits included evaluations of lower respiratory tract infections (bronchitis, pneumonia and asthmatic bronchitis), and the development of neuro-motor skills (using a neuro-development table for 0-6-year-old children) (18). Infants were classified under four categories based on their prognoses: i) Infants with recurrent infection of the respiratory tract plus delayed neuro-development, ii) infants with recurrent infection of the respiratory tract, iii) infants with delayed neuro-development, and iv) normal. A classification of recurrent infection of the respiratory tract indicated at least three separate infections of the lower respiratory tract. Neuro-development was examined by developmental quotient (DQ). DQ was evaluated using five parameters, including gross motor movements, adaptability, fine motor movements, language, and individual-social interaction, as previously determined (18). DQ was calculated as follows: For a $0-1$ year-old child, there was 12 groups which represent each month. In each group, 1 point was weighted for each parameter. For a 1-3 year-old child, there was 4 groups which represent each quarter. In each group, 3 points were weighted for each parameter. The calculation was as follows: $\mathrm{DQ}=(\mathrm{sum}$ of all points in each group $\div 5) \div$ actual age $\mathrm{x} 100$. DQ $<85$ was defined as delayed development, as previously defined (18).

Statistical analysis. Continuous variables are presented as means and standard deviations. Independent t-tests were used to compare the differences between infants with or without complications. One-way analysis of variance with Bonferroni post hoc testing was used to compare differences among different results of prognosis. Categorical variables were presented as counts and percentages. Chi-square tests or Fisher's exact tests were performed for group comparisons where appropriate. Multivariable logistic regression was performed to investigate which factors were associated with prognosis, delayed neuro-development and repeated infection of the respiratory tract. The factors included in the multivariable model were: Gender, gestational age, weight, weight change/per day, intra-uterine infection, premature rupture of membrane, PDA, PDA closure time, type of PDA closure, invasive ventilation duration, non-invasive ventilation duration, application of steroids, steroid treatment, duration of steroid application, complications, BPD severity, pulmonary hemorrhage, ROP, ROP requiring surgical treatments, level III (or higher) intracranial hemorrhage, hypothyroidism, eosinophil, $\mathrm{pH}$, partial pressure of $\mathrm{CO}_{2}$, partial pressure of $\mathrm{O}_{2}$ and $\mathrm{O}_{2}$ concentration.

All statistical analyses were performed using SPSS statistical software version 22 for Windows (IBM Corp., Armonk, New York, USA). A two-tailed P-value $<0.05$ was considered to indicate a statistically significant result.

\section{Results}

Baseline characteristics and comparisons between infants with and without complications. A total of 81 infants 
Table I. Baseline distribution and comparisons between infants with and without complications.

\begin{tabular}{|c|c|c|c|c|}
\hline Variables & Total $(\mathrm{N}=81)$ & Complications $(\mathrm{N}=53)$ & No complications $(\mathrm{N}=28)$ & P-value \\
\hline Gender, n (\%) & & & & 0.288 \\
\hline Male & $58(71.60)$ & $40(75.47)$ & $18(64.29)$ & \\
\hline Female & $23(28.40)$ & $13(24.53)$ & $10(35.71)$ & \\
\hline Gestational age, weeks & $28.75 \pm 1.44$ & $28.7 \pm 1.38$ & $28.86 \pm 1.57$ & 0.624 \\
\hline Weight, $g$ & $1,242.04 \pm 278.58$ & $1,216.7 \pm 256.73$ & $1,290 \pm 315.22$ & 0.263 \\
\hline Twins or multiple births, n (\%) & $20(24.69)$ & $13(24.53)$ & $7(25)$ & 0.963 \\
\hline Premature rupture of membrane, $\mathrm{h}$ & $29.88 \pm 58.79$ & $26.49 \pm 55.59$ & $36.29 \pm 65$ & 0.479 \\
\hline Intra-uterine infection, $\mathrm{n}(\%)$ & $52(64.20)$ & $32(60.38)$ & $20(71.43)$ & 0.324 \\
\hline PDA, n (\%) & $64(79.01)$ & $42(79.25)$ & $22(78.57)$ & 0.944 \\
\hline PDA closure type, n (\%) & & & & 0.244 \\
\hline Surgery & $19(23.46)$ & $12(22.64)$ & $7(25)$ & \\
\hline Drugs & $19(23.46)$ & $15(28.3)$ & $4(14.29)$ & \\
\hline Natural closure & $25(30.86)$ & $16(30.19)$ & $9(32.14)$ & \\
\hline Surgery + drugs & $2(2.47)$ & $0(0)$ & $2(7.14)$ & \\
\hline PDA closure time, days & $12.95 \pm 11.19$ & $13.91 \pm 12.25$ & $11.14 \pm 8.78$ & 0.246 \\
\hline Invasive ventilation duration, days & $11.91 \pm 10.25$ & $13.78 \pm 11.3$ & $8.36 \pm 6.73$ & $0.008^{\mathrm{a}}$ \\
\hline Non-invasive ventilation duration, days & $16.33 \pm 10.82$ & $16.77 \pm 11.06$ & $15.5 \pm 10.51$ & 0.618 \\
\hline Oxygen therapy duration, days & $50.21 \pm 20.53$ & $51.36 \pm 20.6$ & $48.04 \pm 20.58$ & 0.492 \\
\hline BPD severity, n (\%) & & & & 0.056 \\
\hline Severe & $9(11.11)$ & $7(13.21)$ & $2(7.14)$ & \\
\hline Moderate & $16(19.75)$ & $14(26.42)$ & $2(7.14)$ & \\
\hline Mild & $56(69.14)$ & $32(60.38)$ & $24(85.71)$ & \\
\hline
\end{tabular}

${ }^{\mathrm{a}} \mathrm{P}<0.05$ between infants with and without complications. PDA, patent ductus arteriosus; BPD, bronchopulmonary dysplasia.

(58 males and 23 females) were included in this study. The mean weight of the study population was $1,242.04 \pm 278.58 \mathrm{~g}$; the mean gestational age was $28.75 \pm 1.44$ weeks; the mean premature rupture of membrane was $29.88 \pm 58.79 \mathrm{~h}$; the mean patent ductus arteriosus (PDA) closure time was 12.95 \pm 11.19 days; the mean invasive ventilation duration was $11.91 \pm 10.25$ days; the mean non-invasive ventilation duration was $16.33 \pm 10.82$ days; and the mean duration of oxygen therapy was $50.21 \pm 20.53$ days. There were 9 infants with severe BPD, 16 infants with moderate BPD and 56 infants with mild BPD (Table I).

A total of 53 infants had complications while 28 infants had no complications. The mean duration of invasive ventilation was significantly higher in infants with complications compared with those without complications $(13.78 \pm 11.3$ vs $8.36 \pm 6.73$ days, $\mathrm{P}=0.008)$. There were no significant differences between infants with and without complications among the other factors (Table I).

Comparison of infants in different prognosis groups. An analysis of prognoses indicated that 43 infants had a normal prognosis, 11 infants had repeated infections of the respiratory tract plus delayed neuro-development, 19 infants had repeated infections of the respiratory tract, and 8 infants had delayed neuro-development. The mean durations of invasive as well as non-invasive ventilation were significantly higher in infants with repeated infections of the respiratory tract and delayed neuro-development compared with infants who had a normal prognosis (invasive ventilation duration, $21.91 \pm 10.9$ vs. $8.24 \pm 8.05$ days, $\mathrm{P}<0.001$; non-invasive ventilation duration, $24.18 \pm 11.42$ days vs. $13.05 \pm 7.35$ days, $\mathrm{P}=0.01$ ). The mean duration of oxygen therapy was also significantly longer in infants with repeated infections of the respiratory tract and delayed neuro-development compared with infants who had a normal prognosis, infants who had repeated infections of the respiratory tract, and infants in the delayed neuro-development group $(78.27 \pm 22.02$ vs. $40.72 \pm 10.29,54.79 \pm 24.69$ and $51.75 \pm 8.38$ days, respectively, $\mathrm{P}<0.05)$. There were significant differences in types of PDA closure, BPD severity, application of steroids, hypothyroidism and ROP (all $\mathrm{P}<0.05$ ) among the four groups. There was a significantly higher incidence of severe BPD, steroid application and ROP among infants with repeated infection of the respiratory tract plus delayed neuro-development compared with infants in the other groups $(\mathrm{P}<0.05)$. Infants with delayed neuro-development had a significantly higher rate of hypothyroidism compared with infants in the other groups ( $\mathrm{P}=0.007$; Table II).

Comparisons of the effects of different interventions in infants with or without complications. Of the 81 infants, 53 had oxygen-dependent complications $<28$ days after birth. After interventions, oxygen inhalation was discontinued in 12 patients and oxygen concentration reduced in 26 patients, while oxygen therapy was unchanged for 15 patients. Follow-up revealed significant differences in prognosis as well 


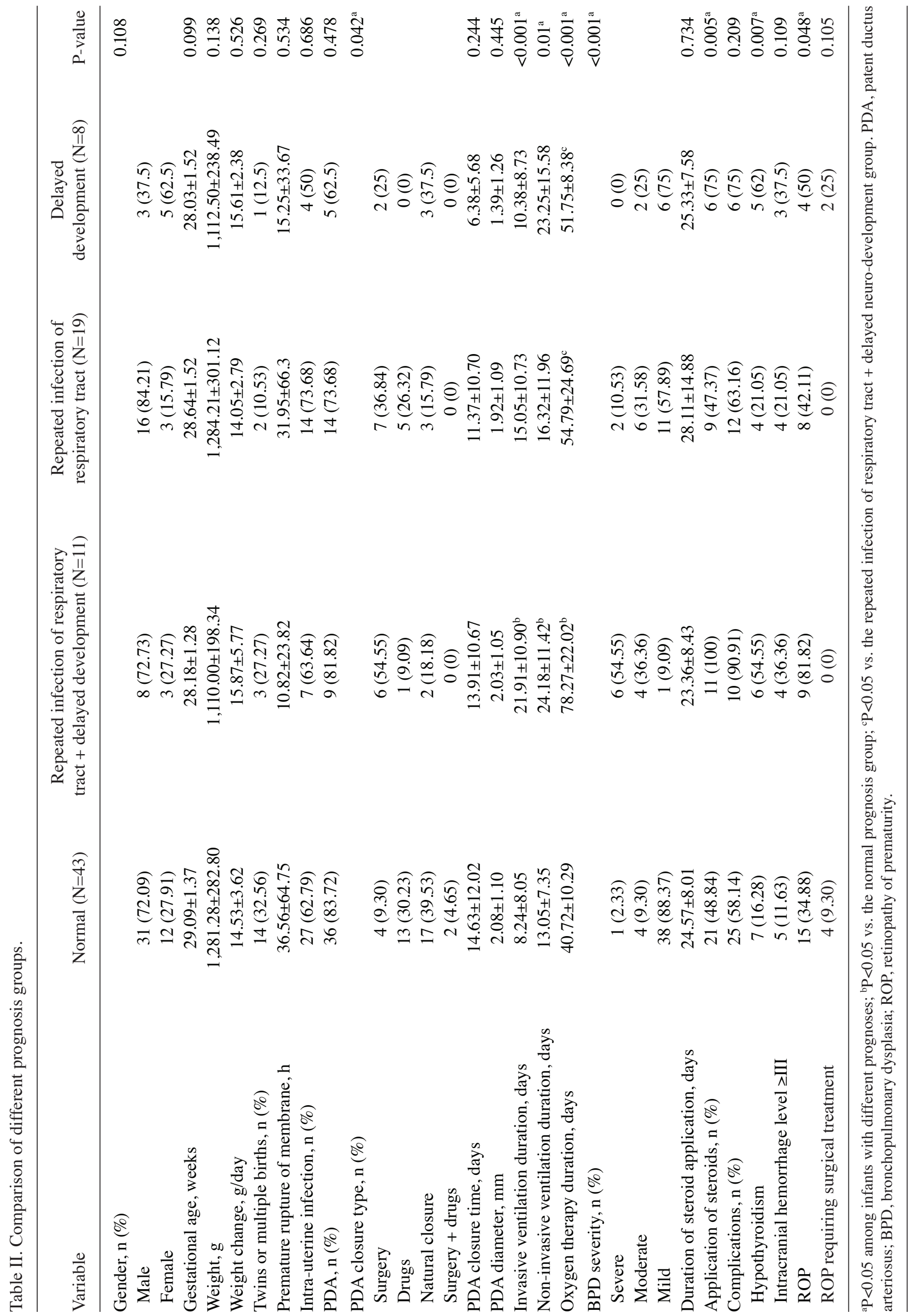


Table III. Comparisons among infants with different intervention effects.

\begin{tabular}{|c|c|c|c|c|}
\hline Variable & $\begin{array}{l}\text { Ceased oxygen inhalation } \\
\qquad(\mathrm{N}=12)\end{array}$ & $\begin{array}{l}\text { Improvement } \\
\qquad(\mathrm{N}=26)\end{array}$ & $\begin{array}{l}\text { Ineffectiveness } \\
\qquad(\mathrm{N}=15)\end{array}$ & P-value \\
\hline BPD severity, n (\%) & & & & 0.306 \\
\hline Severe & $1(8.33)$ & $2(7.69)$ & $4(26.67)$ & \\
\hline Moderate & $2(16.67)$ & $7(26.92)$ & $5(33.33)$ & \\
\hline Mild & $9(75)$ & $17(65.38)$ & $6(40)$ & \\
\hline Prognosis, n (\%) & & & & 0.097 \\
\hline Normal & $0(0)$ & $5(19.23)$ & $5(33.33)$ & \\
\hline $\begin{array}{l}\text { Repeated infection of respiratory } \\
\text { tract }+ \text { delayed development }\end{array}$ & $2(16.67)$ & $6(23.08)$ & $4(26.67)$ & \\
\hline Repeated infection of respiratory tract & $1(8.33)$ & $2(7.69)$ & $3(20)$ & \\
\hline Delayed development & $9(75)$ & $13(50)$ & $3(20)$ & \\
\hline Pneumonia & $5(41.67)$ & $11(42.31)$ & $7(46.67)$ & 1.000 \\
\hline Atelectasis & $1(8.33)$ & $5(19.23)$ & $1(6.67)$ & 0.573 \\
\hline Anemia & $5(41.67)$ & $13(50)$ & $7(46.67)$ & 0.936 \\
\hline PDA & $7(58.33)$ & $23(88.46)$ & $12(80)$ & 0.142 \\
\hline NEC & $1(8.33)$ & $3(11.54)$ & $0(0)$ & 0.439 \\
\hline Hydrocephalus & $3(25)$ & $1(3.85)$ & $1(6.67)$ & 0.123 \\
\hline Sepsis & $1(8.33)$ & $4(15.38)$ & $2(13.33)$ & 1.000 \\
\hline Gastroesophageal reflux disease & $2(18.18)$ & $0(0)$ & $0(0)$ & $0.041^{\mathrm{a}}$ \\
\hline Cardiac insufficiency & $0(0)$ & $4(15.38)$ & $1(6.67)$ & 0.487 \\
\hline CMV infection & $0(0)$ & $0(0)$ & $3(20)$ & $0.029^{\mathrm{a}}$ \\
\hline
\end{tabular}

${ }^{\mathrm{a}} \mathrm{P}<0.05$ among infants with different interventions. BPD, bronchopulmonary dysplasia; PDA, patent ductus arteriosus; NEC, necrotizing enterocolitis; CMV, cytomegalovirus.

as in the efficacy of interventions between patients receiving different interventions. Paired comparisons demonstrated a significant difference between the recurrent respiratory tract infection plus developmental retardation group and the recurrent respiratory tract infection group $(\mathrm{P}=0.0466)$. There was also a significant difference between the recurrent respiratory tract infection plus developmental retardation group and the normal control group $(\mathrm{P}=0.0009)$.

The effects of intervention in these infants were identified to be significantly associated with gastroesophageal reflux disease and cytomegalovirus infection (CMV). There was a significant occurrence of gastroesophageal reflux disease among infants in whom intervention resulted in cessation of inhaled oxygen administration $(\mathrm{P}=0.041)$, and a significant incidence of CMV infection among infants in whom intervention was ineffective $(\mathrm{P}=0.029$; Table III).

Results of multivariable logistic regression. Among the factors examined in this study, BPD severity, gestational age and PDA closure time were demonstrated to be significantly associated with prognosis in the multivariable model. Higher BPD severity indicated higher odds of a poor prognosis [odds ratio $(\mathrm{OR})=9.82, \mathrm{P}=0.0002)$; higher gestational age and PDA closure time indicated lower odds of poor prognosis (gestational age, $\mathrm{OR}=0.61, \mathrm{P}=0.021$; PDA closure time, $\mathrm{OR}=0.94$, $\mathrm{P}=0.043$; Table IV).

For delayed development, when all factors with clinical meaning were included in the multivariable model, BPD severity, duration of non-invasive ventilation, hypothyroidism and level III (or above) intracranial hemorrhage were identified to be significantly associated with delayed development. The odds of delayed development were significantly increased as the $\mathrm{BPD}$ severity increased $(\mathrm{OR}=3.904, \mathrm{P}=0.006)$, as the duration of non-invasive ventilation increased $(\mathrm{OR}=1.07, \mathrm{P}=0.038)$, in infants with hypothyroidism $(\mathrm{OR}=11.23, \mathrm{P}=0.002)$ and level III (or above) intracranial hemorrhage ( $\mathrm{OR}=7.41, \mathrm{P}=0.02$; Table IV).

For repeated infection of the respiratory tract, following the inclusion of all factors with clinical meaning in the multivariable model, BPD severity was determined to be significantly associated with repeated infection of the respiratory tract. The odds of repeated infection of the respiratory tract were significantly increased as the BPD severity increased $(\mathrm{OR}=5.72$, $\mathrm{P}=0.001$; Table IV).

\section{Discussion}

In this retrospective study, it was shown that the major clinical features that influenced the short-term prognosis of infants with BPD (until a corrected gestational age of 12 months) included duration of invasive ventilation, duration of oxygen therapy, application of steroids, type of PDA closure, BPD severity and hypothyroidism.

Gestational age has been shown to be predictive for BPD risk on postnatal days 1 and 3 , and respiratory support on postnatal days 7, 14, 21 and 28 (19). An NICHD study of 
Table IV. Results of multivariable logistic regression.

\begin{tabular}{|c|c|c|}
\hline Outcome variable & OR $(95 \% \mathrm{CI})$ & P-value \\
\hline \multicolumn{3}{|l|}{ Prognosis } \\
\hline BPD severity & $9.82(2.97-32.49)$ & 0.0002 \\
\hline Gestational age & $0.61(0.40-0.93)$ & 0.021 \\
\hline PDA closure time & $0.94(0.89-0.998)$ & 0.043 \\
\hline \multicolumn{3}{|c|}{ Delayed development } \\
\hline BPD severity & $3.904(1.48-10.32)$ & 0.006 \\
\hline $\begin{array}{l}\text { Non-invasive } \\
\text { ventilation time }\end{array}$ & 1.07 (1.004-1.14) & 0.038 \\
\hline \multicolumn{3}{|l|}{ Hypothyroidism } \\
\hline Yes & $11.23(2.40-52.46)$ & 0.002 \\
\hline No & Ref. & \\
\hline \multicolumn{3}{|c|}{$\begin{array}{l}\text { Intracranial hemorrhage } \\
\text { level } \geq \text { III }\end{array}$} \\
\hline Yes & $7.41(1.31-41.88)$ & 0.02 \\
\hline No & Ref. & \\
\hline \multicolumn{3}{|c|}{$\begin{array}{l}\text { Repeated infection of } \\
\text { respiratory tract }\end{array}$} \\
\hline BPD severity & $5.72(2.37-13.81)$ & 0.001 \\
\hline \multicolumn{3}{|c|}{$\begin{array}{l}\text { Factors with clinical meaning were included in the multivariable } \\
\text { model; only factors significantly associated with outcomes (prog- } \\
\text { nosis, delayed development or repeated infection of respiratory } \\
\text { tract) are presented. OR, odds ratio; CI, confidence interval; BPD } \\
\text { bronchopulmonary dysplasia; PDA, patent ductus arteriosus; ROP } \\
\text { retinopathy of prematurity; Ref., reference. }\end{array}$} \\
\hline
\end{tabular}

4,866 premature infants who had a birth weight of $\leq 1,000 \mathrm{~g}$ and a gestational age of $<32$ weeks revealed that infants of gestational age 25.7 weeks developed BPD, while those of gestational age $\sim 27.8$ weeks did not (12). However, the mean gestational age of the premature infants with BPD in the present study was $28.75 \pm 1.44$ weeks. Similarly, although previous studies revealed an inverse correlation between birth weight and the severity of BPD, and only $15 \%$ of premature infants with a birth weight of 1,000-1,250 $\mathrm{g}$ were reported to have a higher than moderate severity of BPD $(14,20)$, BPD severity was higher than moderate in $28.3 \%$ of the present study population (birth weight, $1,242 \pm 278.58 \mathrm{~g}$ ). The reasons for these discrepancies could be the lower level of treatment facilities available in developing countries compared with developed countries.

Mechanical ventilation over the course of a few days or weeks is known to result in progressively worsening pulmonary function, increasing demands on oxygen concentration level and respiratory failure, leading to BPD (10). This was consistent with the results of the present study, which revealed significantly higher mean durations of invasive and non-invasive ventilation, and a longer duration of oxygen therapy in infants with repeated infections of the respiratory tract plus delayed neuro-development compared with infants who had a normal prognosis. These data suggest that shorter durations of oxygen therapy were associated with less severe BPD, and an improved prognosis.
The current definition of BPD is not based on the assessment of lung function or physiology, but involves a subjective assessment of oxygen requirement and ventilation support $(2,4,21)$. In the present study, the roles of factors such as combined ventilator-related pneumonia, atelectasis, PDA, reflux, sepsis and necrotizing enterocolitis, which could play a role in the reliance of oxygen therapy beyond 28 days were investigated. Some patients had multiple complications, such as anemia combined with pneumonia, pneumonia combined with atelectasis or PDA combined with anemia and pneumonia (data not shown). Interventions to resolve complications resulted in cessation of oxygen therapy in 12 infants, and decreased oxygen therapy in 26 infants, while interventions were ineffective in 15 infants. It is possible that the 12 patients $(14.8 \%)$ who ceased oxygen therapy did not have real BPD. Differences in the efficacy of interventions between different groups indicated that interventions for complications $<28$ days after birth may predict a better prognosis if oxygen inhalation is discontinued. It remains to be determined whether these infants continue to fulfill the criteria for BPD diagnosis. It is possible that infants who continue to rely on oxygen therapy for $>28$ days due to complications may progress to chronic lung injury (12). However, it is notable that waiving oxygen therapy in the majority of the premature infants with BPD was impacted by the clinical existence of complications in addition to subsequent damage to the lungs leading to the durations of oxygen therapy being prolonged. It is possible that genetic susceptibility could play a role in infants with BPD who have pneumonia, atelectasis, anemia, PDA, CMV infection and cardiac failure, for whom it was not possible to cease oxygen therapy following intervention.

The results of the present study indicated that a prolonged duration of mechanical ventilation induced more complications during the hospital stay. The major complications in the group which ceased oxygen therapy following interventions were anemia and heart failure, PDA, reflux and hydrocephalus, when compared with the group which exhibited improvement and the group in which interventions were ineffective. However, treatment of anemia and heart failure in the improved group and the ineffective group did not result in cessation of oxygen therapy, suggesting that anemia and heart failure did not play a role in induction of BPD. Notably, the group with cessation of oxygen therapy had fewer patients with pneumonia and atelectasis, which are considered to be factors that require the initiation of oxygen therapy. This suggests that recurrent lung infection and atelectasis, which are causes of long-term oxygen reliance, could play a role in the induction of BPD. These data indicate that reliance on oxygen therapy for $>28$ days may be due to external factors, and premature infants who require oxygen therapy for $>28$ days due to non-respiratory system diseases (such as central respiratory failure and diaphragm paralysis), should not be categorized as having BPD, unless respiratory distress exists.

A previous study investigating the impact of BPD on long-term prognosis, suggested that long-term prognosis was not associated with the duration of oxygen therapy (including the requirement for oxygen therapy at 36 weeks PMA) (14). One study suggested that BPD was associated with the length of hospital stay for respiratory distress, but not the number of hospital stays (22), while another study indicated that BPD was 
correlated with an increased number of hospital stays (23). The severity of BPD has been shown to be positively correlated with poor prognosis of the respiratory system (24). In the present study, logistic regression analysis revealed that factors associated with the prognosis of premature infants with BPD include the duration of invasive and non-invasive ventilation, duration of oxygen therapy, type of PDA closure, BPD severity, application of steroids, hypothyroidism and ROP. A previous study reported that persistent PDA was significantly associated with increased duration of mechanical ventilation, oxygen treatment and rates of BPD (25). Sadeck et al (26) reported that the conservative approach to PDA was associated with high mortality, the surgical approach to the occurrence of BPD at 36 weeks, and pharmacological treatment was protective for the outcome of mortality or BPD at 36 weeks. The present study had similar observations. In children with low birth weight, surgical PDA ligation may cause atelectasis, pulmonary infection, sepsis and other complications contributing to worsening of the severity of BPD. Based on the present study's finding that the durations of invasive ventilation and oxygen therapy were highest in the recurrent infection of respiratory tract plus delayed neuro-development group, and second highest in the recurrent infection group, it is likely that the durations of invasive ventilation and oxygen therapy may be good prognostic indicators.

BPD and the administration of steroids after birth have previously been shown to be high risk factors of delayed neuro-development in ELBW infants (18-22 months corrected gestational age) $(27,28)$. Other studies indicated that the administration of steroids after birth in order to prevent and cure BPD could increase the incidence rate of cerebral palsy $(23,29-33)$. The results of the present study demonstrated a strong association of the application of steroids with recurrent infection of the respiratory tract plus delayed neuro-development $(100 \%)$, and with delayed neuro-development (75\%). However, $48.8 \%$ of infants who were administered steroids had a normal prognosis, and were therefore at risk of developing combined respiratory system disease and delayed neuro-development. Infants with delayed neuro-development had the highest incidence of hypothyroidism, followed by infants in the recurrent infection of the respiratory tract plus delayed neuro-development group. Notably, persistent hyperthyrotropinemia has been shown to result in poor neurological outcomes (34).

In conclusion, the present study indicated that the duration of invasive ventilation, duration of oxygen therapy, application of steroids and hypothyroidism were among the clinical factors associated with the prognosis of premature infants with BPD (12 months corrected gestational age). On the basis of these results, it is suggested that shortening the duration of invasive ventilation and correcting thyroid function are potential clinical strategies to improve prognosis in these infants. Additionally, BPD severity appears to be an indicator of prognosis, since there was a significantly lower incidence of combined recurrent respiratory infection and delayed neuro-development among infants who ceased oxygen therapy within 36 weeks (PMA). Therefore, prognosis may also be improved by strengthening the management and optimizing the follow-up of the high-risk BPD infants on the basis of the clinical features. However, a major limitation of this study is that it was conducted as a single center, single arm study, with no controls or parallel groups. This may introduce bias into the current study and therefore, a further multi-center study may help overcome this limitation.

\section{References}

1. Jobe AH and Bancalari E: Bronchopulmonary dysplasia. Am J Respir Crit Care Med 163: 1723-1729, 2001.

2. Islam JY, Keller RL, Aschner JL, Hartert TV and Moore PE: Understanding the short- and long-term respiratory outcomes of prematurity and bronchopulmonary dysplasia. Am J Respir Crit Care Med 192: 134-156, 2015.

3. Dumpa V, Northrup V and Bhandari V: Type and timing of ventilation in the first postnatal week is associated with bronchopulmonary dysplasia/death. Am J Perinatol 28: 321-330, 2011.

4. Merritt TA, Deming DD and Boynton BR: The 'new' bronchopulmonary dysplasia: Challenges and commentary. Semin Fetal Neonatal Med 14: 345-357, 2009.

5. Northway WH Jr, Rosan RC and Porter DY: Pulmonary disease following respirator therapy of hyaline-membrane disease. Bronchopulmonary dysplasia. N Engl J Med 276: 357-368, 1967.

6. O'Brodovich HM and Mellins RB: Bronchopulmonary dysplasia. Unresolved neonatal acute lung injury. Am Rev Respir Dis 132: 694-709, 1985

7. Sahni R, Ammari A, Suri MS, Milisavljevic V, Ohira-Kist K, Wung JT and Polin RA: Is the new definition of bronchopulmonary dysplasia more useful? J Perinatol 25: 41-46, 2005.

8. Iyer NP and Mhanna MJ: The role of surfactant and non-invasive mechanical ventilation in early management of respiratory distress syndrome in premature infants. World J Pediatr 10: 204-210, 2014.

9. Sweet DG, Carnielli V, Greisen G, Hallman M, Ozek E, Plavka R, Saugstad OD, Simeoni U, Speer CP, Vento M, et al: European consensus guidelines on the management of neonatal respiratory distress syndrome in preterm infants-2013 update. Neonatology 103: 353-368, 2013.

10. Bancalari E, Claure N and Sosenko IR: Bronchopulmonary dysplasia: Changes in pathogenesis, epidemiology and definition. Semin Neonatol 8: 63-71, 2003.

11. Shennan AT, Dunn MS, Ohlsson A, Lennox K and Hoskins EM: Abnormal pulmonary outcomes in premature infants: Prediction from oxygen requirement in the neonatal period. Pediatrics 82: 527-532, 1988.

12. Ehrenkranz RA, Walsh MC, Vohr BR, Jobe AH, Wright LL, Fanaroff AA, Wrage LA and Poole K; National Institutes of Child Health and Human Development Neonatal Research Network: Validation of the national institutes of health consensus definition of bronchopulmonary dysplasia. Pediatrics 116: 1353-1360, 2005.

13. Walsh MC, Wilson-Costello D, Zadell A, Newman N and Fanaroff A: Safety, reliability, and validity of a physiologic definition of bronchopulmonary dysplasia. J Perinatol 23: 451-456, 2003.

14. Davis PG, Thorpe K, Roberts R, Schmidt B, Doyle LW and Kirpalani H; Trial Indomethacin Prophylaxis in Preterms Investigators: Evaluating 'old' definitions for the 'new' bronchopulmonary dysplasia. J Pediatr 140: 555-560, 2002.

15. Parad RB, Davis JM, Lo J, Thomas M, Marlow N, Calvert S, Peacock JL and Greenough A: Prediction of respiratory outcome in extremely low gestational age infants. Neonatology 107: 241-248, 2015.

16. Natarajan G, Pappas A, Shankaran S, Kendrick DE, Das A, Higgins RD, Laptook AR, Bell EF, Stoll BJ, Newman N, et al: Outcomes of extremely low birth weight infants with bronchopulmonary dysplasia: Impact of the physiologic definition. Early Hum Dev 88: 509-515, 2012.

17. Baraldi E, Carraro S and Filippone M: Bronchopulmonary dysplasia: Definitions and long-term respiratory outcome. Early Hum Dev 85 (10 Suppl): S1-S3, 2009.

18. Gao ZJ, Jiang Q, Cheng DZ, Yan XX, Chen Q and Xu KM: Application of single nucleotide polymorphism-microarray and target gene sequencing in the study of genetic etiology of children with unexplained intellectual disability or developmental delay. Zhonghua Er Ke ZaZhi 54: 740-745, 2016.

19. Laughon MM, Langer JC, Bose CL, Smith PB, Ambalavanan N, Kennedy KA, Stoll BJ, Buchter S, Laptook AR, Ehrenkranz RA, et al: Prediction of bronchopulmonary dysplasia by postnatal age in extremely premature infants. Am J Respir Crit Care Med 183: 1715-1722, 2011. 
20. Lemons JA, Bauer CR, Oh W, Korones SB, Papile LA, Stoll BJ, Verter J, Temprosa M, Wright LL, Ehrenkranz RA, et al: Very low birth weight outcomes of the national institute of child health and human development neonatal research network, January 1995 through December 1996. NICHD Neonatal Research Network. Pediatrics 107: E1, 2001.

21. Jobe AH: What is BPD in 2012 and what will BPD become? Early Hum Dev 88 (Suppl 2): S27-S28, 2012.

22. Gregoire MC, Lefebvre F and Glorieux J: Health and developmental outcomes at 18 months in very preterm infants with bronchopulmonary dysplasia. Pediatrics 101: 856-860, 1998.

23. Smith VC, Zupancic JA, McCormick MC, Croen LA, Greene J, Escobar GJ and Richardson DK: Rehospitalization in the first year of life among infants with bronchopulmonary dysplasia. J Pediatr 144: 799-803, 2004.

24. American Association of Pediatrics CoFaN: Postnatal corticosteroids to treat or prevent lung disease in preterm infants. Pediatrics 109: 330-338, 2002.

25. Saldeno YP, Favareto V and Mirpuri J: Prolonged persistent patent ductus arteriosus: Pot ential perdurable anomalies in premature infants. J Perinatol 32: 953-958, 2012.

26. Sadeck LS, Leone CR, Procianoy RS, Guinsburg R, Marba ST, Martinez FE, Rugolo LM, Moreira ME, Fiori RM, Ferrari LL, et al: Effects of therapeutic approach on the neonatal evolution of very low birth weight infants with patent ductus arteriosus. J Pediatr (Rio J) 90: 616-623, 2014.

27. Vohr BR, Wright LL, Dusick AM, Mele L, Verter J, Steichen JJ, Simon NP, Wilson DC, Broyles S, Bauer CR, et al: Neurodevelopmental and functional outcomes of extremely low birth weight infants in the national institute of child health and human development neonatal research network, 1993-1994. Pediatrics 105: 1216-1226, 2000.
28. Peltoniemi OM, Lano A, Yliherva A, Kari MA and Hallman M; Neonatal Hydrocortisone Working Group: Randomised trial of early neonatal hydrocortisone demonstrates potential undesired effects on neurodevelopment at preschool age. Acta Paediatr 105: 159-164, 2016.

29. Yeh TF, Lin YJ, Huang CC, Chen YJ, Lin CH, Lin HC, Hsieh WS and Lien YJ: Early dexamethasone therapy in preterm infants: A follow-up study. Pediatrics 101: E7, 1998.

30. O'Shea TM, Kothadia JM, Klinepeter KL, Goldstein DJ, Jackson BG, Weaver RG III and Dillard RG: Randomized placebo-controlled trial of a 42-day tapering course of dexamethasone to reduce the duration of ventilator dependency in very low birth weight infants: Outcome of study participants at 1-year adjusted age. Pediatrics 104: 15-21, 1999.

31. Halliday HL, Ehrenkranz RA and Doyle LW: Early postnatal ( $<96$ hours) corticosteroids for preventing chronic lung disease in preterm infants. Cochrane Database Syst Rev: CD001146, 2003.

32. Halliday HL, Ehrenkranz RA and Doyle LW: Moderately early (7-14 days) postnatal corticosteroids for preventing chronic lung disease in preterm infants. Cochrane Database Syst Rev: CD001144, 2003.

33. Halliday HL, Ehrenkranz RA and Doyle LW: Delayed (>3 weeks) postnatal corticosteroids for chronic lung disease in preterm infants. Cochrane Database Syst Rev: CD001145, 2003.

34. Chung ML, Yoo HW, Kim KS, Lee BS, Pi SY, Lim G and Kim EA: Thyroid dysfunctions of prematurity and their impacts on neurodevelopmental outcome. J Pediatr Endocrinol Metab 26: 449-455, 2013. 